\title{
Anemia falciforme y resistencia a la malaria. Revisión narrativa
}

\section{Sickle cell anemia and resistance to malaria. Narrative review}

\author{
Mariana Roldan-Isaza ${ }^{1}$, Laura Herrera-Almanza ${ }^{1,}$, Alejandro Hernández-Martinez ${ }^{1}$, \\ Lina María Martínez-Sanchez ${ }^{2}$.
}

\section{RESUMEN}

La enfermedad de células falciformes es una hemoglobinopatía autosómica recesiva producida por la mutación del gen de la cadena $\beta$-globina, que genera la sustitución de valina por el ácido glutámico en la posición del sexto aminoácido de la hemoglobina. Existen diversos mecanismos moleculares y celulares por los cuales se explica

\begin{abstract}
Sickle cell disease is an autosomal recessive hemoglobinopathy, caused by the mutation of the $\beta$-globin chain gene that results in the replacement of valine by glutamic acid at the position of the sixth amino acid in the hemoglobin. There are various molecular and cellular mechanisms by which its pathophysiology
\end{abstract}

\section{Historial del artículo:}

Fecha de recepción: 20/02/2020

Fecha de aprobación: 24/06/2020

1 Universidad Pontificia Bolivariana. Escuela de Ciencias de la Salud, Facultad de Medicina, Estudiante de Medicina. Medellín, Colombia.

2 Universidad Pontificia Bolivariana. Escuela de Ciencias de la Salud, Facultad de Medicina. Bacterióloga, Especialista en Hematología, Magister en Educación Universitaria.

Correspondencia: Mariana Roldan Isaza. Dirección: Calle 78 B N 72 a 109: Universidad Pontificia Bolivariana, Escuela de Ciencias de la Salud, Facultad de Medicina. Medellín, Colombia. Teléfono: +57(4) 4488388. Correo electrónico: mariana.roldan@upb.edu.co.

Como citar este artículo: Roldan-Isaza M, Herrera-Almanza L, Hernández-Martínez A, Martínez-Sánchez LM. Anemia falciforme y resistencia a la malaria. Revisión narrativa. Revista de la Facultad de Ciencias de la Salud de la Universidad del Cauca. $2020 ; 22$ (2):34-42. https://doi.org/10.47373/rfcs.2020.v22.1510 
su fisiopatología y, gracias a su actual entendimiento, se encuentran en investigación clínica y preclínica nuevos agentes farmacológicos. La hemoglobina falciforme (HbS), que es la consecuencia de dicha mutación, se relaciona como una forma de protección contra la malaria en los heterocigotos; sin embargo, el estado homocigoto (HbSS) puede estar asociado con una mayor susceptibilidad a las formas graves de malaria y sus complicaciones. Dicha relación de protección en heterocigotos se evidencia en niveles más bajos deparasitemia y de aparición más tardía, lo que se ha tratado de explicar por diversas teorías. Este artículo tiene como objetivo revisar la relación entre la enfermedad de células falciformes y la malaria, presentando la fisiopatología, el tratamiento y los mecanismos de resistencia a la malaria en paciente con enfermedad de células falciformes para lograr un entendimiento más amplio de la enfermedad.

Palabras clave: Malaria, Anemia de Células Falciformes, Hemoglobina Falciforme. (DeCS)

\section{INTRODUCCIÓN}

La anemia (o enfermedad) de células falciformes (ECF) y la malaria son co-endémicas en África; la ECF es una hemoglobinopatía causada por una mutación autosómica recesiva en la cadena de $\beta$-globina que resulta en la sustitución de valina por el ácido glutámico en la posición del sexto aminoácido de la hemoglobina (1-4).

La malaria es una enfermedad ocasionada por 6 especies de parásitos capaces de infectar al hombre; estos son: Plasmodium falciparum, Plasmodium vivax, Plasmodium ovale wallickeri, Plasmodium ovale curtisi, Plasmodium malariae y Plasmodium knowlesi (5). De estos microorganismos, los principales agentes etiológicos son $P$. falciparum y $P$. vivax transmitidos por mosquitos hembras del género Anopheles (5).

Existe un vínculo entre la presencia de hemoglobina falciforme $(\mathrm{HbS})$ y protección contra la malaria en los heterocigotos; sin embargo, el estado homocigoto (HbSS) está asociado con una mayor susceptibilidad a las formas severas de malaria $(2,3,6-8)$. Se ha evidenciado que en los pacientes con ECF la parasitemia se presenta con niveles más bajos y de manera más tardía, lo que permite al organismo desarrollar una respuesta inmune adaptativa mejorada (4). is explained and thanks to its current understanding, new pharmacological agents are under clinical and preclinical research. Sickle hemoglobin (HbS), which is the consequence of this mutation, is related as a form of protection against malaria in heterozygotes; however, homozygous status (HbSS) may be associated with increased susceptibility to severe forms of malaria and their complications. This protection relationship in heterozygotes is evidenced in lower levels ofparasitaemia and later onset, that various theories had tried to explain. This article aims to review the relationship between sickle cell disease and the protection it generates in malaria infection, in addition to exposing the pathophysiology, treatment and mechanism of resistance of malaria in sickle cell disease patients to achieve a broader understanding of the disease

Key words: Malaria; Anemia, Sickle Cell; Hemoglobin, Sickle. (MeSH)

La malaria se ha encontrado, en adultos con ECF, asociada a crisis agudas y hospitalizaciones frecuentes y en los nińos, a anemia severa y mayor mortalidad (2). A pesar de que la prevalencia general de malaria en personas con ECF es baja, se ha reportado que entre los pacientes hospitalizados la mortalidad es mayor (2,3). Por ello, se considera dar profilaxis a todos los pacientes con ECF en zonas endémicas de malaria, para reducir las crisis de células falciformes y la necesidad de utilización de hemoderivados (9). Este artículo tiene como objetivo revisar la relación entre la ECF y la malaria, para lograr un entendimiento más amplio de la enfermedad.

\section{METODOLOGÍA}

Se llevó a cabo una búsqueda de la literatura en las bases de datos Lilacs, Medline y Science Direct, usando los descriptores o términos MeSH: Malaria, Anemia de Células Falciformes y Hemoglobina Falciforme. La fecha final de búsqueda fue abril de 2020.

\section{EPIDEMIOLOGÍA}

Aproximadamente el $7 \%$ de la población general es portadora de algún tipo de trastorno de la hemoglobina, entre las que destacan la drepanocitosis y la talasemia $(10,11)$. La ECF o drepanocitosis 
es la enfermedad hematológica hereditaria más común con una distribución heterogénea, siendo frecuentemente encontrada en la población con ascendencia africana $(12,13)$. El genotipo predominante es el homocigoto (HbSS) (14).

En todo el mundo, se estima que 312.000 nińos nacen con ECF por ańo y el $75 \%$ de ellos son de África subsahariana. En Uganda, 15.000 nińos nacen con la enfermedad y de estos $50-80 \%$ mueren anualmente antes de los 5 ańos (1-3,7). En las Américas afecta a 1 de cada 365 nacidos afroamericanos y a 1 de cada 16.300 hispanoamericanos (15).

En Colombia, la prevalencia en la población afrodescendiente se encuentra entre el 11 y el $12 \%(17,18)$. Anualmente nacen 20.000 nińos con rasgo drepanocítico, mientras que 500 nińos son homocigotos para la enfermedad. La prevalencia de la HbS en infantes heterocigotos en Buenaventura y Valle del Cauca es del 19\% (19,20). Las poblaciones que tienen mayor riesgo se encuentran en Choó, Antioquia, Valle del Cauca y Narińo, aunque pueden encontrarse en otras partes del país (21).

La Organización Mundial de la Salud (OMS) informó que durante el ańo 2018 fueron reportados 228 millones de casos de malaria en el mundo, con una distribución heterogénea, siendo más común en África, donde se encuentran el 93\% de los casos reportados. El P. falciparum fue el agente etiológico encontrado en el $99.7 \%$ de los casos en África, mientras que en América y Asia el P. vivax representó el $75 \%$ y $47 \%$ de los casos, respectivamente. Según este mismo informe, 405.000 pacientes fallecieron y los menores de 5 ańos fueron el grupo etario más afectado (22).

En América Latina, especialmente en las áreas tropicales y subtropicales, existen varias regiones endémicas de malaria y la región amazónica es donde se concentra la mayor carga de enfermedad de los casos reportados para América del Sur (23).

En Colombia, entre 2016 y 2018, se reportaron en total 257.623 casos de malaria $(24,25)$, el parásito más prevalente es el Plasmodium vivax, siendo más común en la cuenca Amazónica Norte, el Caribe, Sucre, Antioquia y Córdoba, mientras que el Plasmodium falciparum se encuentra en las costas del Pacífico y algunas regiones de la cuenca amazónica y del Magdalena (26).

Hace 50 ańos se reportó por primera vez que la presencia de ECF le brindaba a los pacientes resistencia contra la malaria (12); se ha reportado que dicha enfermedad reduce el riesgo de malaria grave causada por $P$. falciparum en un $90 \%$ (3). Esta hipótesis se planteó al observar que la hemoglobina $S$ era más común en aquellas poblaciones en donde la malaria constituía una enfermedad endémica y recibió el nombre de
"Malaria hipótesis" lo que sugería que la mutación heredada de uno de los padres proporcionaba un grado de protección contra la malaria. Sin embargo, cuando los individuos eran homocigotos, se observaba un incremento de la letalidad por la alta tasa de hemólisis y vasooclusión (27).

\section{FISIOPATOLOGÍA}

La ECF se define como una entidad en la que se generan eritrocitos en forma de hoz a partir de la herencia de la HbS. El espectro de la ECF es amplio; varía desde el genotipo homocigoto (HbSS), heterocigoto (HbAS), sin talasemia previamente $\left(\mathrm{HbS}^{\circ}\right)$, con antecedente de talasemia $\left(\mathrm{HbSB}^{+}\right)$ y otras hemoglobinopatías (HbSC).

Cuando la concentración de la HbS en los eritrocitos se acerca a $30 \mathrm{mg} / \mathrm{dl}$, asociada con la desoxigenación, se produce la polimerización de la HbS, formando los cuerpos tactoides; es decir, fibras individuales o agregadas que conllevan a que el eritrocito se vuelva rígido, elongado, forme espículas en sus bordes y adopte forma de hoz $(12,28)$. Esto último se debe a que el nuevo residuo de valina se une a una porción hidrófoba entre el residuo de fenilalanina y leucina en la posición 85 y 88 de la cadena de $\beta$-globina.

Se ha visto que el cambio de la membrana del eritrocito, la disfunción endotelial y la inflamación, comprenden mecanismos fisiopatológicos que influyen en la variabilidad de la ECF. La lesión de los lípidos de la membrana de los eritrocitos, producida por los estados de desoxigenación, genera exposición de micropartículas tales como la fosfatidilserina al medio externo, lo que se cree que es una de las causas del aumento de los eventos protrombóticos, debido a la conversión de protrombina a trombina.

Adicionalmente, se presenta hemólisis intravascular producida por el paso de los hematíes lesionados a través de la microvasculatura, opsonización y destrucción de los eritrocitos (12). Asimismo, hay hemólisis extravascular mediada por el reconocimiento y eliminación de los eritrocitos dańados por medio de los monocitos y macrófagos esplénicos y tisulares (29).

La drepanocitosis es una endoteliopatía en donde existe incremento de las moléculas de adhesión como E-selectina, P-selectina y VCAM, lo que potencia la vasculopatía y el estado de inflamación crónica. Además, existe un incremento en la adhesión de los leucocitos relacionado con una mayor mortalidad, infartos cerebrales silenciosos, accidentes cerebrovasculares hemorrágicos y síndrome de tórax agudo (12). 


\section{CARACTERÍSTICAS CLIINICAS}

Las manifestaciones clínicas de la ECF son variadas y dependen de la gravedad y el tiempo de evolución de la misma. Los pacientes heterocigotos para la $\mathrm{HbS}$ (HbAS) generalmente son asintomáticos, a diferencia de los homocigotos o en combinación con otra hemoglobina anómala $(12,13,16)$. La principal manifestación de esta enfermedad son las llamadas crisis drepanocíticas, las cuales se caracterizan por crisis vasooclusivas, dolorosas y recurrentes (30). El dolor se produce dependiendo de donde se genere la crisis, siendo más común el dolor óseo $(11,31)$.

La esplenomegalia es moderada y transitoria en los primeros 10 ańos de vida, en los cuales tiene mayor riesgo de generar anemia severa por hiperesplenismo crónico o secuestro esplénico agudo. Posteriormente, debido a los múltiples infartos, el bazo se fibrosa y atrofia, generando una asplenia funcional, lo que aumenta el riesgo de infecciones por microorganismos encapsulados como Streptococcus pneumoniae y Haemophilus influenzae; es raro documentar secuestro luego de esta edad $(32,33)$.

Algunas de las principales complicaciones que se pueden presentar son el síndrome torácico agudo, el accidente cerebrovascular hemorrágico o isquémico, priapismo, sepsis, asplenia funcional, secuestro esplénico agudo, aplasia pura transitoria eritroide y crisis hemolíticas $(12,16,32)$.

Con respecto a la relación de ECF y la malaria, se sabe que la resistencia que confiere esta primera contra dicha enfermedad infecciosa se manifiesta solo en los pacientes que son heterocigotos para la $\mathrm{HbS}$, proporcionándole una protección parcial al paciente, debido a que limita la parasitemia. Sin embargo, en los pacientes homocigotos con una baja parasitemia puede aumentar la hemólisis y los cuadros de vasooclusión $(27,33)$.

\section{TRATAMIENTO}

Actualmente se realiza un manejo multidisciplinario de la patología con el objetivo de reducir la morbimortalidad con intervenciones como medicamentos, transfusiones sanguíneas y, en algunos casos, trasplante de células madre hematopoyética y terapia génica, debido a que las alternativas curativas hasta el momento son pocas $(34,35)$.

El principal agente farmacológico utilizado para el manejo a largo plazo de estos pacientes es la hidroxiurea, aprobada en 1988 por la Food and Drugs Administration (FDA) (36).
Este medicamento actúa a través de varios mecanismos que mejoran la disponibilidad de la $\mathrm{HbF}$, con un descenso en la HbS, además, disminuye la expresión de moléculas de adhesión y la liberación del óxido nítrico mejorando los síntomas $(36,37)$.

Una revisión Cochrane encontró que la hidroxiurea es efectiva en disminuir la frecuencia de los episodios dolorosos, los eventos neurológicos y las complicaciones agudas tanto en adultos como en nińos (38), aunque se deben vigilar los efectos adversos como la toxicidad dosis-dependiente y los efectos a largo plazo (36).

Las transfusiones crónicas de componentes sanguíneos se consideran el estándar de cuidado para la prevención de accidentes cerebrovasculares, a pesar de presentar riesgos como la sobrecarga de hierro y la aloinmunización $(39,40)$. Teniendo en cuenta los riesgos y la costoefectividad se prefieren alternativas como la hidroxiurea, la cual parece ser segura y efectiva.

El manejo de las crisis vasooclusivas dolorosas incluye intervenciones farmacológicas como opioides, analgésicos no opioides, medicamentos en combinación, oxigenación e hidratación (41). Las intervenciones no farmacológicas, como el entrenamiento físico de resistencia, han mostrado efectos benéficos en la red capilar muscular de pacientes con anemia de células falciformes, por lo que teóricamente podría aportar al manejo y prevención de estas crisis (42). De igual manera, aunque parezca paradójico el uso de la flebotomía en una enfermedad de naturaleza anémica, esta parece disminuir la frecuencia de las crisis vasooclusivas y las hospitalizaciones $(43,44)$.

Los descubrimientos recientes con respecto a los mecanismos fisiopatológicos de la enfermedad a nivel molecular han permitido el desarrollo de nuevos agentes farmacológicos que se encuentran en investigación preclínica y clínica (45). Estos medicamentos incluyen inductores de la $\mathrm{HbF}$, anti-drepanocíticos, antioxidantes, agentes antiadhesivos, antiinflamatorios, anticoagulantes y antiplaquetarios (46). También se han sometido a prueba otros medicamentos como la L-Glutamina, recientemente aprobada por la FDA, y la eritropoyetina recombinante, cuyo uso en la anemia de células falciformes ha demostrado mejorar las concentraciones de hemoglobina, disminuyendo la necesidad de transfusiones $(45,47)$.

Por último, como terapia curativa, el trasplante de células madres hematopoyéticas es la única medida aprobada con este fin, pero existen múltiples barreras para su implementación 
como la falta de donantes compatibles, el rechazo del trasplante y los desenlaces adversos o inciertos a largo plazo (45). La terapia génica es una alternativa curativa de la enfermedad (48); en la anemia falciforme busca reemplazar el gen de la hemoglobina defectuoso con una copia normal de ese gen, para así restaurar la función de la proteína de forma definitiva (49). La terapia génica aún no está disponible en nuestro medio por lo que el trasplante continúa siendo la única terapia curativa a la que se tiene acceso.

\section{PROFILAXIS}

La quimioprofilaxis se ha establecido como una estrategia recomendada para mitigar el impacto de la malaria en los pacientes con ECF que viven en regiones endémicas. Los estudios mencionan que la profilaxis reduce el riesgo de anemia asociada a malaria, los niveles parasitarios en los pacientes con la infección y la presentación de malaria en pacientes con ECF (28). Se han utilizado diversos medicamentos para la quimioprofilaxis, incluyendo cloroquina vía oral de forma semanal acompańada de penicilina benzatínica, pirimetamina de forma semanal y proguanil de forma semanal; sin embargo, la evidencia no es suficiente para recomendar o refutar algún esquema en específico (50).

El incremento de la resistencia a cloroquina y sulfadoxinapirimetamina, dos de los medicamentos más costo-efectivos en la profilaxis para malaria en zonas endémicas, puede representar una barrera importante en la implementación de esta estrategia además de la ausencia de guías y la falta de disponibilidad de los medicamentos $(28,51)$.

\section{RESISTENCIA A LA MALARIA}

La malaria es considerada una enfermedad protozoaria causada por 5 especies de Plasmodium (P. falciparum, P. vivax, P. malariae, P. ovale, P. knowlesi). Su ciclo de vida comprende dos huéspedes: realiza el ciclo asexual (esquizogonia) en el hombre y el ciclo sexual (esporogonia) en el vector Anopheles, teniendo como productos el merozoito y el esporozoito respectivamente. Este último producto mencionado es la forma infecciosa, que se transmite por medio de la picadura del Anopheles hembra, transfusiones de sangre, agujas contaminadas o de modo transplacentario.

Los esporozoitos llegan a los hepatocitos para multiplicarse y formar los merozoitos (esto es conocido como la esquizogonia preeritrocítica), lo que corresponde al periodo de incubación, durante el cual el paciente se encuentra asintomático y no es infeccioso, y que varía entre 9 a 40 días, dependiendo de la especie infecciosa. Posteriormente, los hepatocitos se rompen liberando los merozoitos al torrente sanguíneo e ingresan a los eritrocitos (esto es conocido como esquizogonia eritrocítica), en donde se transforman en trofozoítos y luego a esquizonte; esta etapa corresponde al periodo de síntomas prodrómicos, caracterizados por durar 2 a 3 días y tener síntomas inespecíficos tales como cefalea, mialgia, artralgia, fatiga, dolor torácico y abdominal.

A veces los merozoitos liberados vuelven a entrar a los hepatocitos para realizar esquizogonia eritrocítica o para mantenerse latentes por varios ańos y posteriormente provocar recaídas. Luego, el esquizonte se convierte en merozoitos que se liberan al generarse la hemólisis (paroxismo palúdico); clínicamente consiste en fiebre y escalofríos en intervalos periódicos. Dichos merozoitos podrán ingresar en otros eritrocitos e infectarlos, aunque otros se transformarán en gametocitos, los cuales ingresan al anopheles cuando ingiere sangre de una persona infectada, se genera el ciclo sexual y se forman esporozoitos (52).

Dicho parásito conserva una variabilidad genética con ventajas para la interacción con el huésped, variación antigénica, seńalización, tráfico de proteínas y adhesión. Entre estos genes, unos de los más estudiados son los que codifican para la proteína 1 de la membrana de eritrocitos de P. falciparum (PfEMP1), representando un papel importante en la patogenia mediado por la citoadherencia de los eritrocitos infectados en los tejidos profundos.

Esta proteína puede unirse a diferentes moléculas del huésped,tales como $\alpha 2$-macroglobulina, condroitín sulfato A, complemento 1q, E-selectinas, P-selectinas, receptor de proteína C endotelial, heparán sulfato, Inmunoglobulina G, Inmunoglobulina M, ICAM1 y VCAM1. Dicha unión produce la activación de diferentes respuestas inflamatorias del huésped, que promueve el desarrollo de enfermedades graves y facilita la infección de otros eritrocitos sanos. También tiene la capacidad de generar variación antigénica en la expresión de los 50 a 150 genes var que la codifican, permitiéndole así evadir la respuesta inmune del huésped (53).

La resistencia a la malaria involucra diversos mecanismos genéticos e inmunológicos, que llevan a la presencia de parasitemia leve y lenta, como la producción de anticuerpos específicos, que pueden reducir la gravedad de los síntomas y la mortalidad (54). En otras palabras, la resistencia a la malaria en la ECF involucra respuestas inmunes humorales. 
De acuerdo con lo anterior, se ha demostrado que niveles más altos de respuestas de inmunoglobulina $\mathrm{G}(\mathrm{Ig} G)$ contra Plasmodium falciparum tienen una correlación con la protección clínica en nińos con HbAS; sin embargo, el rol de la IgG en HbSS está menos caracterizado $(6,55)$.

Otros mecanismos que han sido relacionados con la protección de la ECF contra la malaria son:

- Cuando los niveles de oxígeno caen por debajo del $5 \%$ se ha demostrado que se inhibe el crecimiento del parásito intraeritrocítico por la polimerización de $\mathrm{Hb}$ (54-58).

- Mayor tasa de fagocitosis de los eritrocitos falciformes infectados comparados con los eritrocitos normales (54-58).

- Deterioro de la citoadherencia de los eritrocitos parasitados a las células endoteliales microvasculares ya que la proteína de membrana eritrocitaria de $P$. falciparum 1 (PfEMP1) anormal, produce un fallo en la citoadherencia de los eritrocitos parasitados a otras células de hasta un $50 \%$, generando protección al limitar la carga de parásitos e invasión parasitaria. Las alteraciones en las cadenas de la hemoglobina alteran la interacción de PfEMP1 con las proteínas de anclaje, por tanto, se reduce la citoadherencia y los procesos inflamatorios que promueven el desarrollo grave de la enfermedad (38-60).

- La presencia aumentada de inmunidad innata a través de la inhibición de los linfocitos T CD8+ y la regulación de la hemooxigenasa 1 (58-60). En cuanto al rol la hemooxigenasa 1, existen varios estudios que destacan que, al ser una molécula contrarreguladora capaz de eliminar la citotoxicidad del hemo libre, representa una molécula capaz de brindar protección para prevenir el desarrollo de malaria grave, especialmente para la presencia de complicaciones neurológicas (61).

- Papel protector del bazo, se aprecia que los glóbulos rojos de genotipo heterocigoto son menos deformables que los glóbulos rojos homocigotos (HbSS). Por ello, la destrucción preferencial en el bazo de glóbulos rojos $\mathrm{HbS}$ infectados con $P$. falciparum puede ser un factor protector ante una elevada parasitemia (59).

- Otro mecanismo de resistencia descrito se relaciona con la presencia de microARN (miARN - micro ácido ribonucleico), miR-451 y miR-233; estos son más abundantes en las células falciformes en comparación con los glóbulos rojos normales $(60,62)$. Estos compuestos se incorporan covalentemente a los ARNm de P. falciparum, lo que conlleva a inhibir la traducción y, por tanto, genera una reducción significativa en el crecimiento del parásito Figura $1(60,62)$.
Figura 1. Mecanismos asociados a resistencia a malaria en pacientes con $\mathrm{ECF}$

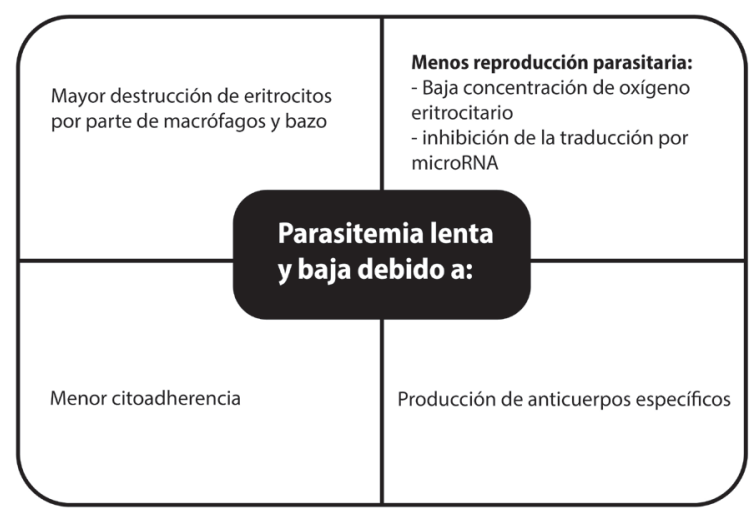

Fuente: Propia de los autores.

Adicionalmente, un estudio mostró que el genotipo heterocigoto $\mathrm{HbS}$ parece ser resistente contra las alteraciones hematológicas de la malaria en los diversos componentes celulares de la sangre como glóbulos blancos, plaquetas, algunos índices de glóbulos rojos, medidas de marcadores de hierro, ferritina, hierro, capacidad total de fijación del hierro y saturación de transferrina (8).

\section{CONCLUSIONES}

La ECF es la hemoglobinopatía hereditaria más común y se debe a la mutación en la cadena de la $\beta$-globina de la hemoglobina. Su fisiopatología comprende varios mecanismos moleculares y celulares por los cuales se produce una inclinación hacia un estado anémico y protrombótico. Se ha descrito que la presencia de ECF puede proteger a los pacientes de formas severas de malaria, debido a que, por diversas vías, en estos pacientes se presenta una parasitemia baja. El tratamiento de la anemia falciforme tiene un enfoque multidisciplinario con el objetivo de reducir la morbimortalidad y el principal agente farmacológico para su manejo hasta el momento es la hidroxiurea.

\section{CONTRIBUCIÓN DE LOS AUTORES}

Todos los autores colaboraron en la redacción y aprobación del final del manuscrito.

\section{CONFLICTOS DE INTERÉS}


No se declara ningún conflicto.

\section{REFERENCIAS}

1. Atiku SM, Louise N, Kasozi DM. Severe oxidative stress in sickle cell disease patients with uncomplicated Plasmodium falciparum malaria in Kampala, Uganda. BMC Infect Dis. 2019;19(1):600. https://doi.org/10.1186/ s12879-019-4221-y

2. Adjei GO, Goka BQ, Enweronu-Laryea CC, Rodrigues OP, Renner L, Sulley AM, et al. A randomized trial of artesunate-amodiaquine versus artemether-lumefantrine in Ghanaian paediatric sickle cell and non-sickle cell disease patients with acute uncomplicated malaria. Malar J. 2014; 13:369. https://doi.org/10.1186/14752875-13-369

3. Eleonore NLE, Cumber SN, Charlotte EE, Lucas EE, Edgar MML, Nkfusai CN,et al. Malaria in patients with sickle cell anaemia: burden, risk factors and outcome at the Laquintinie hospital, Cameroon. BMC Infect Dis. 2020;20(1):40. https://doi.org/10.1186/s12879-0194757-x

4. Diakité SA, Ndour PA, Brousse V, Gay F, Roussel C, Biligui S, et al. Stage-dependent fate of Plasmodium falciparum-infected red blood cells in the spleen and sickle-cell trait-related protection against malaria. Malar J. 2016;15(1):482. https://doi.org/10.1186/s12936-0161522-0

5. Milner DA Jr. Malaria Pathogenesis. Cold Spring Harb Perspect Med. 2018;8(1):a025569. https://doi. org/10.1101/cshperspect.a025569

6. Bwire GM, Majigo M, Makalla R, Nkinda L, Mawazo A, Mizinduko M, et al. Immunoglobulin G responses against falciparum malaria specific antigens are higher in children with homozygous sickle cell trait than those with normal hemoglobin. BMC Immunol. 2019;20(1):12. https://doi.org/10.1186/s12865-019-0294-Z

7. Komba AN, Makani J, Sadarangani M, Ajala-Agbo T, Berkley JA, Newton CR, et al. Malaria as a cause of morbidity and mortality in children with homozygous sickle cell disease on the coast of Kenya. Clin Infect Dis. 2009;49(2):216-22. https://doi.org/10.1086/599834

8. Albiti AH, Nsiah K. Comparative haematological parameters of HbAA and HbAS genotype children infected with Plasmodium falciparum malaria in Yemen. Hematology. 2014;19(3):169-74. https://oiorg/10.1179/ 1607845413Y.0000000113

9. Oniyangi O, Omari AA. Malaria chemoprophylaxis in sickle cell disease.Cochrane Database Syst Rev.
2019;2019(11). https://doi.org/10.1002/14651858. CD003489.pub2

10. Gupta NK, Gupta M. Sickle cell anemia with malaria: a rare case report. Indian J Hematol Blood Transfus. 2014;30 (1):38-40. https://doi.org/10.1007/s12288012-0181-8

11. Rojas-Martínez A., Calderón E., Vidal M.A., Arroyo F., García-Hernández R., Torres L.M. Crisis drepanocítica y tratamiento del dolor. Rev. Soc. Esp. Dolor. 2015; 22 (4): 165-167. https://doi.org/10.4321/S113480462015000400004

12. Azar S, Wong TE. Sickle Cell Disease: A Brief Update. Med Clin North Am. 2017;101(2):375-393. https://doi. org/10.1016/j.mcna.2016.09.009

13. Eller R, da Silva D.B. Evaluation of a neonatal screening program for sickle-cell disease. J Pediatr (Rio J). 2016; 92 (4): 409-413. https://doi.org/10.1016/j.jped.2015.10.002

14. Castro IPS, Viana MB. Cognitive profile of children with sickle cell anemia compared to healthy controls. J Pediatr (Rio J). 2018. https://doi.org/10.1016/j.jped.2018.04.012

15. Zúniga C.P, Martínez G.C, González R.L.M., Rendón C.D.S., Rojas R.N, Barriga C.F. et al . Enfermedad de células falciformes: Un diagnóstico para tener presente. Rev. chil. pediatr. 2018; 89( 4 ): 525-529. https://doi.org/10.4067/ S0370-41062018005000604

16. Acuńa C, Cuero K, Espitia K, Rojas R, Torres R. Anemia drepanocítica y situación en colombia: Revisión. Bio. 2018; 1(3).

17. Castillo M, Oliveros A, Mora A. Association of Thalassemia and Trait, Sickle Cell and Trait and Hemoglobin C with Iron-Deficiency Anemia in Colombians of African Descent. Journal of Life Sciences. 2014; 8 (11): 861-864. Doi: 10.17265/1934-7391/2014.11.001

18. Zavala G, Viera W, Castillo G, Mejía G, Bustillo P, $\mathrm{Fa}_{\neg}$ jardo E, et al. Prevalencia de anemia drepanocítica en población de la comunidad de San Juan, Yoro. Rev. Fac. Cienc. Méd. 2014; 11: 17-25.

19. de Bernal M, Collazos A, Bonilla RD, Tascón EP. Determination of the prevalence of hemoglobin S, C, $\mathrm{D}$, and $\mathrm{G}$ in neonates from Buenaventura, Colombia. Colomb. Med. 2010; 41 (2): 141-147.

20. Huttle A, Maestre GE, Lantigua R, Green NS. Sickle cell in Latin America and the United States [corrected]. Pediatr Blood Cancer. 2015;62(7):1131-6. https://doi. org/10.1002/pbc. 25450

21. Quintero M, Jiménez A. ANEMIA DE CÉLUlaS FALCIFORMES. Gastrohnup. 2012; 14 (2): 27-35.

22. World Health Organization. World Malaria Report 2019. [Consultado el 24 Abr 2020] Disponible en: https://www. who.int/malaria/media/world-malaria-report-2019/es/. 
23. Recht J, Siqueira AM, Monteiro WM, Herrera SM, Herrera S, Lacerda MVG. Malaria in Brazil, Colombia, Peru and Venezuela: current challenges in malaria control and elimination. Malar J. 2017;16(1):273. https://doi. org/10.1186/s12936-017-1925-6

24. Rodríguez-Morales AJ, Suárez JA, Risquez A, VillamilGómez WE, Paniz-Mondolfi A. Consequences of Venezuela's massive migration crisis on imported malaria in Colombia, 2016-2018. Travel Med Infect Dis. 2019; 28:98-99. https://doi.org/10.1016/j.tmaid.2019.02.004

25 . World Health Organization. World Malaria Report 2018. [Consultado el 26 Sept 2020] Disponible en: https://www.who.int/malaria/media/world-malariareport-2018/es/

26. Feged-Rivadeneira A, Ángel A, González-Casabianca F, Rivera C. Malaria intensity in Colombia by regions and populations. PLoS One. 2018;13(9):e0203673. https:// doi.org/10.1371/journal.pone.0203673

27. Cabrera-Zamora MM. Malaria y hemoglobina S: ¿resistencia o protección? Medisur. 2018; 16(4):504-10. https://doi.org/10.12968/npre.2018.16.10.504

28. Aneni EC, Hamer DH, Gill CJ. Systematic review of current and emerging strategies for reducing morbidity from malaria in sickle cell disease. Trop Med Int Health. 2013;18(3):313-27. https://doi.org/10.1111/tmi.12056

29. Kato GJ, Gladwin MT, Steinberg MH. Deconstructing sickle cell disease: reappraisal of the role of hemolysis in the development of clinical subphenotypes. Blood Rev 2007;21(1):37-47. https://doi.org/10.1016/j. blre.2006.07.001

30. Díaz-Morejón L, Rodríguez-Jorge B, García-Sánchez D, León-Rayas Y, Aguilar-Lezcano L, Santacruz-Leonard M. Anemia drepanocítica: características generales de los pacientes a su diagnóstico. Revista Finlay. 2019; 9(1): 2019; 9(1): 4-10. Borrar: Disponible en: http://www. revfinlay.sld.cu/index.php/finlay/article/view/681

31. Ayala Viloria Alfonso J, González Torres Henry J, David Tarud Gabriel J. Anemia de células falciformes: una revisión. Salud, Barranquilla . 2016;32 (3): 513-527. https://doi.org/10.14482/sun.32.2.9750

32. Zúńiga C. Pamela, Martínez G. Cindy, González R. Lina M., Rendón C. Diana S., Rojas R. Nicolás, Barriga C. Francisco et al. Enfermedad de células falciformes: Un diagnóstico para tener presente. Rev. chil. pediatr. . 2018; 89(4): 525-529. https://doi.org/10.4067/S037041062018005000604

33. Cervera Bravo A, Rueda Núnez F, Benedit Gómez M, López-Vélez Pérez R, Sánchez Guilarte J. Drepanocitosis y paludismo: Agravación de la enfermedad de base. An Esp Pediatr. 1997;47:191-4.
34. Tisdale JF, Thein SL, Eaton WA. Treating sickle cell anemia. Science. 2020;367(6483):1198-1199. https:// doi.org/10.1126/science.aba3827

35. Monus T, Howell CM. Current and emerging treatments for sickle cell disease. JAAPA. 2019;32(9):1-5. https://doi. org/10.1097/01.JAA.0000578812.47138.99

36. Fernandes Q. Therapeutic strategies in Sickle Cell Anemia: The past present and future. Life Sci. 2017; 178:100-108. https://doi.org/10.1016/j.lfs.2017.03.025

37. Yahouédéhou SCMA, Adorno EV, da Guarda CC, Ndidi US, Carvalho SP, Santiago RP, et al. Hydroxyurea in the management of sickle cell disease: pharmacogenomics and enzymatic metabolism. Pharmacogenomics J. 2018;18(6):730-739. https://doi.org/10.1038/s41397018-0045-1

38. Nevitt SJ, Jones AP, Howard J. Hydroxyurea (hydroxycarbamide) for sickle cell disease. Cochrane Database Syst Rev. 2017;4:CD002202. https://doi. org/10.1002/14651858.CD002202.pub2

39. Hasson C, Veling L, Rico J, Mhaskar R. The role of hydroxyurea to prevent silent stroke in sickle cell disease: Systematic review and meta-analysis. Medicine (Baltimore). 2019;98(51): e18225. https://doi. org/10.1097/MD.0000000000018225

40. DeBaun MR, Gordon M, McKinstry RC, Noetzel MJ, White DA, Sarnaik SA, et al. Controlled trial of transfusions for silent cerebral infarcts in sickle cell anemia. $\mathrm{N}$ Engl J Med. 2014;371(8):699-710. https://doi.org/10.1056/ NEJMoa1401731

41. Cooper TE, Hambleton IR, Ballas SK, Johnston BA, Wiffen PJ. Pharmacological interventions for painful sickle cell vaso-occlusive crises in adults. Cochrane Database Syst Rev. 2019;2019(11). https://doi.org/10.1002/14651858. CD012187.pub2

42. Merlet AN, Messonnier LA, Coudy-Gandilhon C, Béchet D, Gellen B, Rupp T, et al. Beneficial effects of endurance exercise training on skeletal muscle microvasculature in sickle cell disease patients. Blood. 2019;134(25):22332241. https://doi.org/10.1182/blood.2019001055

43. Padaro E, Kueviakoe IMD, Agbétiafa K, Magnang H, Mawussi K, Layibo Y, Vovor A. Therapeutic phlebotomy during major sickle cell disease in Togo. Med Sante Trop. 2019;29(1):106-107. https://doi. org/10.1155/2019/4539675

44. Estcourt LJ, Fortin PM, Hopewell S, Trivella M, Wang WC. Blood transfusion for preventing primary and secondary stroke in people with sickle cell disease. Cochrane Database Syst Rev. 2017;1(1):CD003146. https://doi. org/10.1002/14651858.CD003146.pub3 
45. Kapoor S, Little JA, Pecker LH. Advances in the Treatment of Sickle Cell Disease. Mayo Clin Proc. 2018;93(12):18101824. https://doi.org/10.1016/j.mayocp.2018.08.001

46. Ataga KI, Stocker J. The trials and hopes for drug development in sickle cell disease. Br J Haematol. 2015;170(6):768-80. https://doi.org/10.1111/bjh.13548

47. Ferreira FA, Benites BD, Costa FF, Gilli S, Olalla-Saad ST. Recombinant erythropoietin as alternative to red cell transfusion in sickle cell disease. Vox Sang. 2019;114(2):178-181. https://doi.org/10.1111/vox.12750

48. Demirci S, Uchida N, Tisdale JF. Gene therapy for sickle cell disease: An update. Cytotherapy. 2018 Jul;20(7):899910. https://doi.org/10.1016/j.jcyt.2018.04.003

49. Olowoyeye A, Okwundu CI. Gene therapy for sickle cell disease. Cochrane Database Syst Rev. 2018;11:CD007652. https://doi.org/10.1002/14651858.CD007652.pub6

50. Oniyangi 0 , Omari AA. Malaria chemoprophylaxis in sickle cell disease. Cochrane Database Syst Rev. 2019; (11): CD003489.pub2. https://doi.org/10.1002/14651858. CD003489.pub2

51. Ndegeulaya EJ, Bwire GM, Sangeda RZ, Mloka, D, Tungaraza F, et al. Utilization patterns of malaria chemoprophylaxis among Tanzanian children attending sickle cell clinic in Dar es Salaam tertiary hospitals. Malar J. 2019;18(1):393. https://doi.org/10.1186/s12936-0193029-y

52. Basu S, Sahi PK. Malaria: An Update. Indian J Pediatr. 2017;84 (7):521-528. https://doi.org/10.1007/s12098017-2332-2

53. Su XZ, Lane KD, Xia L, Sá JM, Wellems TE. Plasmodium Genomics and Genetics: New Insights into Malaria Pathogenesis, Drug Resistance, Epidemiology, and Evolution. Clin Microbiol Rev. 2019;32(4):e00019-19. https://doi.org/10.1128/CMR.00019-19

54. López C, Saravia C, Gomez A, Hoebeke J, Patarroyo MA. Mechanisms of genetically-based resistance to malaria. Gene. 2010;467(1-2):1-12. https://doi.org/10.1016/j. gene.2010.07.008

55. Miura K, Diakite M, Diouf A, Doumbia S, Konate D, Keita AS et al. Relationship between malaria incidence and IgG levels to Plasmodium falciparum merozoite antigens in Malian children: impact of hemoglobins S and C. PLoS One. 2013;8(3):e60182. https://doi.org/10.1371/journal. pone. 0060182

56. Nasr A, Saleh AM, Eltoum M, Abushouk A, Hamza A, Aljada A, et al. Antibody responses to P. falciparum Apical Membrane Antigen 1(AMA-1) in relation to haemoglobin S (HbS), HbC, G6PD and ABO blood groups among Fulani and Masaleit living in Western Sudan. Acta Trop. 2018; 182:115-123. https://doi.org/10.1016/j. actatropica.2018.02.030
57. Tan X, Traore B, Kayentao K, Ongoiba A, Doumbo S, Waisberg M, et al. Hemoglobin S and C heterozygosity enhances neither the magnitude nor breadth of antibody responses to a diverse array of Plasmodium falciparum antigens. J Infect Dis. 2011;204(11):1750-61. https://doi. org/10.1093/infdis/jir638

58. Beaudry JT, Krause MA, Diakite SA, Fay MP, Joshi G, Diakite M, et al. Ex-vivo cytoadherence phenotypes of Plasmodium falciparum strains from Malian children with hemoglobins A, S, and C. PLoS One. 2014;9(3):e92185. https://doi.org/10.1371/journal.pone.0092185

59. Diakité SA, Ndour PA, Brousse V, Gay F, Roussel C, Biligui S, et al. Stage-dependent fate of Plasmodium falciparum-infected red blood cells in the spleen and sickle-cell trait-related protection against malaria. Malar J. 2016;15(1):482. https://doi.org/10.1186/s12936-016$1522-0$

60. Archer NM, Petersen N, Clark MA, Buckee CO, Childs LM, Duraisingh MT. Resistance to Plasmodium falciparum in sickle cell trait erythrocytes is driven by oxygendependent growth inhibition. Proc Natl Acad Sci U S A. 2018;115(28):7350-7355. https://doi.org/10.1073/ pnas. 1804388115

61. Taylor SM, Cerami C, Fairhurst RM. Hemoglobinopathies: Slicing the Gordian Knot of Plasmodium falciparum Malaria Pathogenesis. PLoS Pathog. 2013; 9(5): e1003327. https://doi.org/10.1371/journal.ppat.1003327

62. Duraisingh M, Lodish H. Sickle Cell MicroRNAs Inhibit the Malaria Parasite. Cell Host Microbe. 2012; 12(2): 127-128. https://doi.org/10.1016/j.chom.2012.08.001 